\title{
DEVELOPMENT OF INNOVATIVE MECHANICAL FLEXIBLE SOLAR ARRAY ARCHITECTURE
}

\author{
Bernard BOULANGER ${ }^{(1)}$, Yannick BAUDASSÉ ${ }^{(1)}$, François GUINOT ${ }^{(1)}$, Laurent D'ABRIGEON $^{(1)}$, Mikaël \\ THIBAUDEAU ${ }^{(1)}$, Marina HEIM ${ }^{(2)}$, Fabrice BUFFE ${ }^{(2)}$, Etienne RAPP $^{(2)}$ \\ (1) THALES ALENIA SPACE France, 5 allée des Gabians BP 99,06156 Cannes La Bocca Cedex (France) Email: Bernard.Boulanger@thalesaleniaspace.com \\ (2) CNES France, 18 avenue Edouard Belin, 31401 Toulouse Cedex 9(FRANCE) Email: Marina.Heim@.cnes.fr
}

\begin{abstract}
Flexible solar array architecture is proposed instead of rigid one, for high power solar array used from space tug mission to GEO satellite one, but also for specific scientific mission. THALES ALENIA SPACE has developed with Centre National d'Etudes Spatiales (CNES) support, innovative mechanical flexible solar array architecture, using $22 \mathrm{~m}$ long carbon tape-springs. The first part of the study was to design, predict, verify carbon tape-springs mechanical behaviour during deployment and coiling phases at room temperature. THALES ALENIA SPACE built mechanical flexible solar array mock-up full scale width / half scale length and performed deployment and rolling-up tests.

The second part was to design, predict carbon tapesprings mechanical behaviour with large temperature range due to solar array missions. THALES ALENIA SPACE used again flexible solar array mock-up, performed deployment/coiling tests with innovative tape springs.
\end{abstract}

This $11^{\text {th }}$ ESPC paper describes results of these development activities and the THALES ALENIA SPACE forecast on this flexible solar array market.

\section{INTRODUCTION}

The double facing deployed tape-springs concept (see Fig. 1) is a real technological gap and has been patented by THALES ALENIA SPACE. This concept permits to have a very light structure with high stiffness and stability in its deployed configuration.

Functional tests realized on a full scale flexible solararray demonstrator and correlation with mathematical models reinforce the confidence in the reliability of the system.

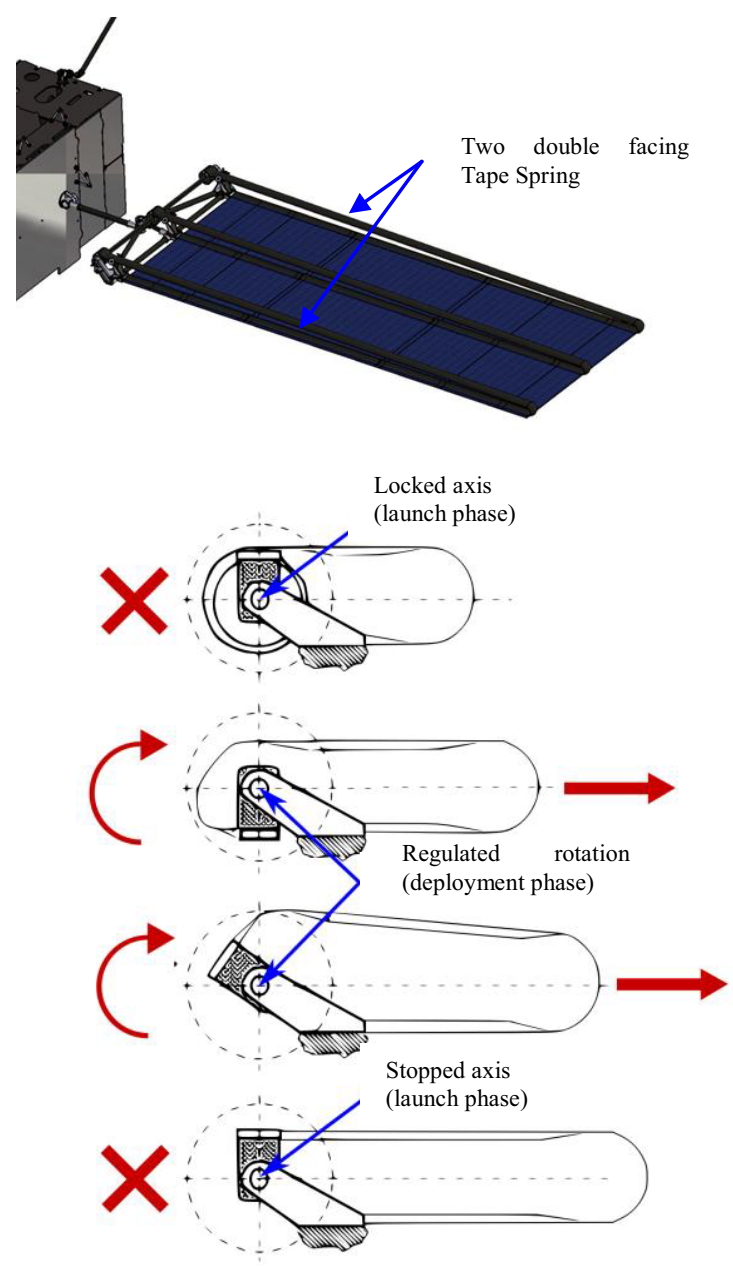

Figure 1. Solar wing with double facing deployed tapesprings concept.

The deployment is made reliable thanks to a gear motor control system in parallel of tape springs actuation:

- deployment control (kinematics, speed regulation)

- in case of "harsh point", possibility to briefly over-motorize

Coiling the substrate offers major advantages :

- High modularity/accommodation,

- Very high power range till 35-50KW.

- Optimized weight/power ratio

- Optimized stowed volume under the fairing

- Rolling/Unrolling on demand 
This innovative concept has been developed for solar array but could be also used for additional applications such as thermal shield baffles for telescopes.

\section{CARBON TAPE SPRING DEVELOPMENT}

\subsection{Stiffness considerations}

The rollable solar array mechanical structure (THALES ALENIA SPACE patent) is based on tape-springs coiling/uncoiling. The global concept consists of tapesprings bent into two. One tape-springs extremity is fixed while the other one is allowed to rotate around a mandrel. On this mechanical structure, a flexible blanket supporting the flexible solar cells and the electrical routing is attached.

The tape-spring design (geometric properties and material choice) has been done to be in agreement with the classic rigid solar array specifications: the frequency of the first vibration mode when deployed must be $\geq 0.1$ $\mathrm{Hz}$.

The mechanical design optimization has been done using a finite element software (MSC Marc). First a model validation has been done thanks to experimental comparisons on tape-springs samples.

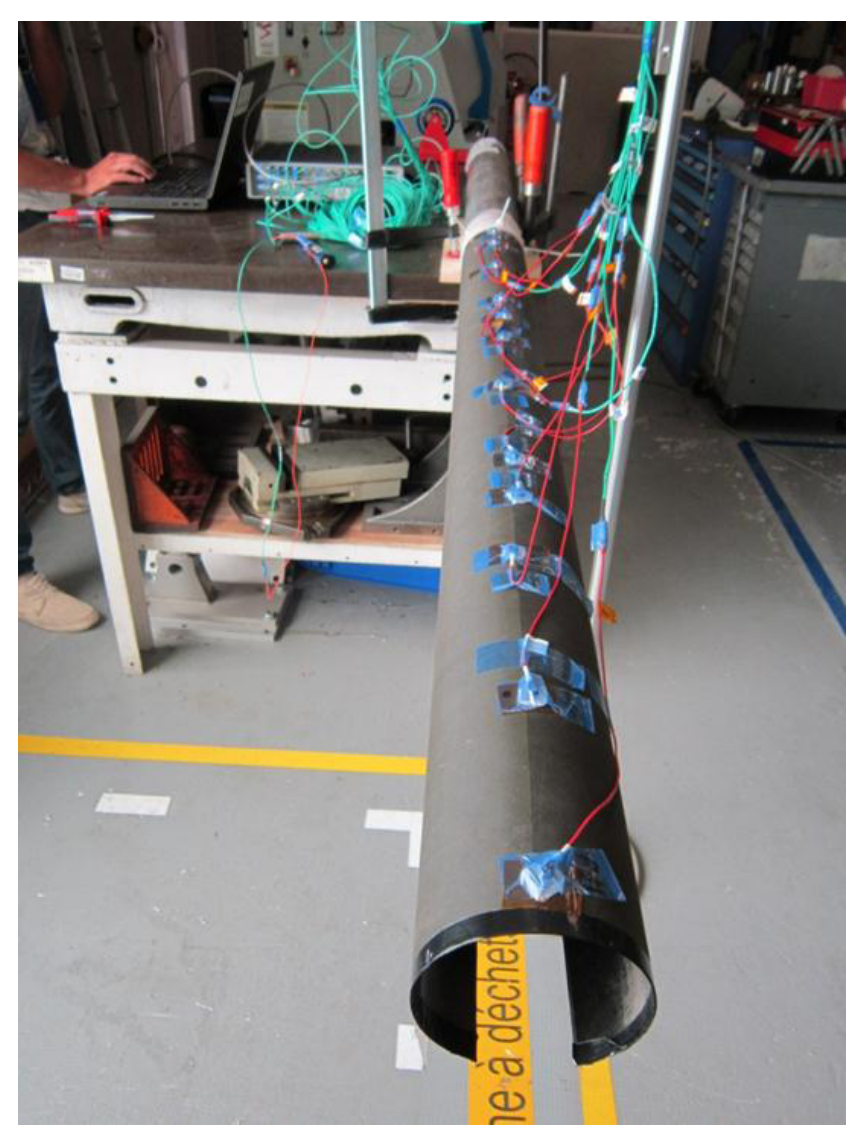

Figure 2 shows the experimental set-up that has been used to identify the modal behavior of a tape-spring sample to be compared to simulation results. Accelerometers have been regularly placed along the tape-spring in order to measure the response of a shock transmitted through an impact hammer.
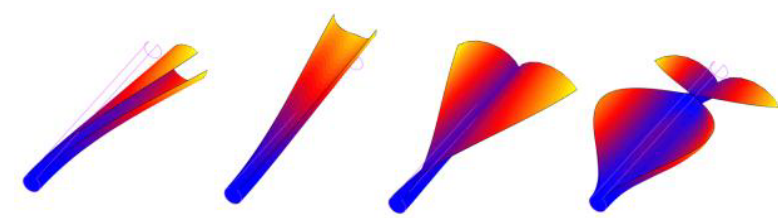

Figure 3. Modal shapes, simulation results

\begin{tabular}{|c|c|c|}
\hline Mode & $\begin{array}{c}\text { Theoretical } \\
\text { Expected } \\
\text { Frequency }(\mathrm{Hz})\end{array}$ & $\begin{array}{c}\text { Frequency } \\
\text { obtained by test } \\
(\mathrm{Hz})\end{array}$ \\
\hline 1 & - & 15 \\
\hline 2 & 28 & 29 \\
\hline 3 & 41 & 43 \\
\hline 4 & 67 & 64 \\
\hline
\end{tabular}

Table 1. Frequencies comparison.

Table 1 shows that the simulations perfectly predict the modal behavior of tape-springs. It is now assumed that this modeling procedure can be used to identify the frequencies of the global flexible solar array (comprising flexible blanket, stiffeners), and to validate the geometric and material choices.

The full scale global finite element model consists in two tape-springs made of carbon fibers lay-up which are modeled as shell, so is the flexible blanket (considered as a stacking of different materials such as copper and solar cells). The stiffeners are modeled as beams.

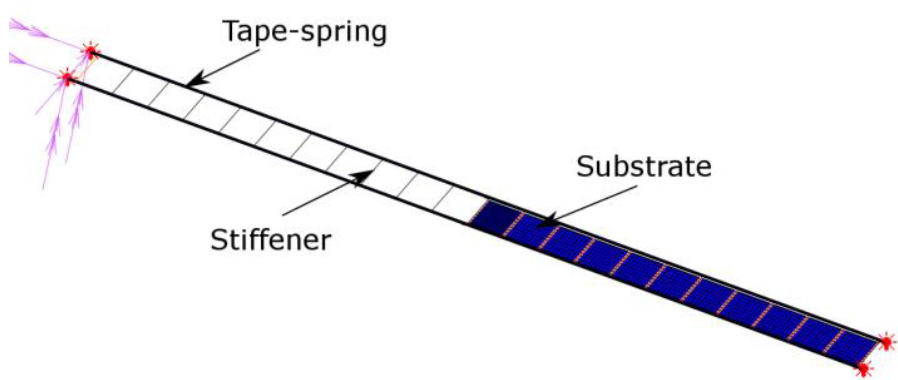

Figure 4. Full scale global finite element model.

Figure 2. Experimental setup for modal analysis. 
The model described in figure 4 is used to perform a highly nonlinear analysis to set the flexible solar array in its deployed configuration. The modal analysis is then carried out around this stable position.
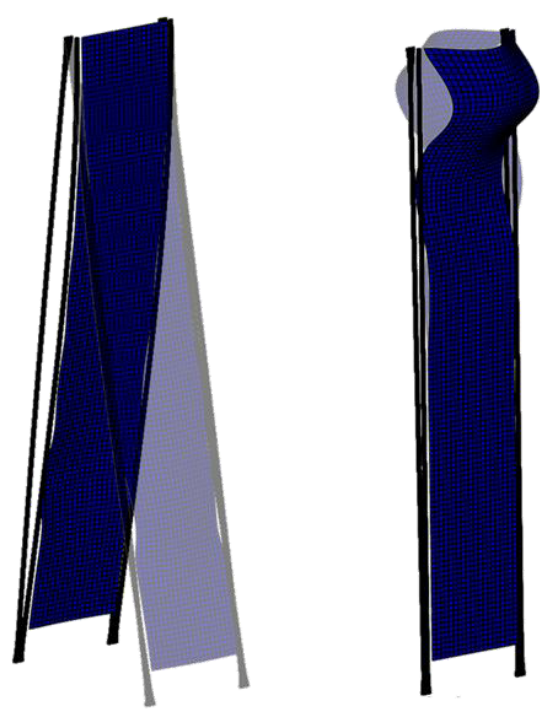

Figure 5. First 2 modal shapes

Several simulations have been run in order to identify the tape-springs characteristics that give a $0.1 \mathrm{~Hz}$ for the $1^{\text {st }}$ mode frequency. These geometrical properties and material characteristics lead to a mass of $28 \mathrm{~kg}$ for the 2 tape-springs, whereas the blanket weights $74 \mathrm{~kg}$.

This tape-springs design have been used to produce several $22 \mathrm{~m}$ long tape-springs in order to build and test functional mockups as it can be seen in figures 6 and 7 .

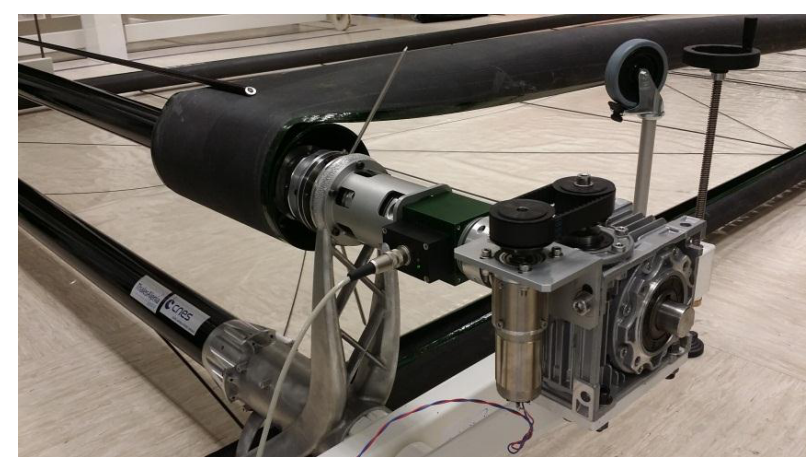

Figure 6. Deployment test and torque measurement

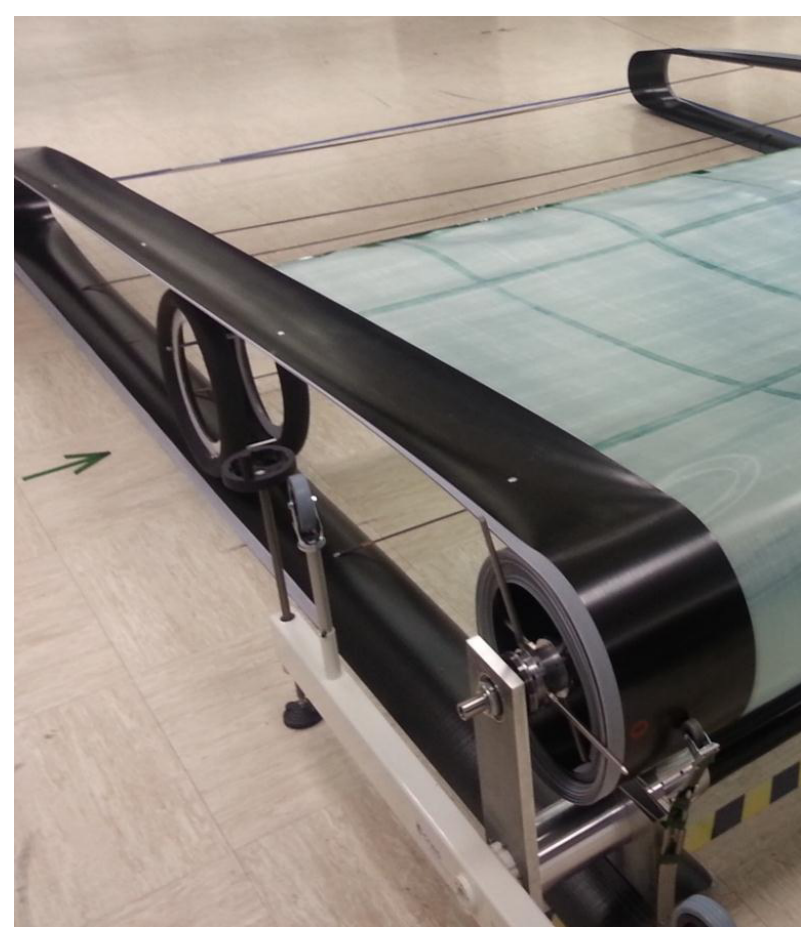

Figure 7. Flexible equivalent substrate mounted on the tape-springs structure.

Several mechanical tests have been carried out on the tape-springs themselves and on the mock-up. First the production quality has been checked and validated thanks to bending tests on tape-springs samples.

Figure 8. Nonlinear bending test performed on a $3 \mathrm{~m}$ long tape-spring sample.

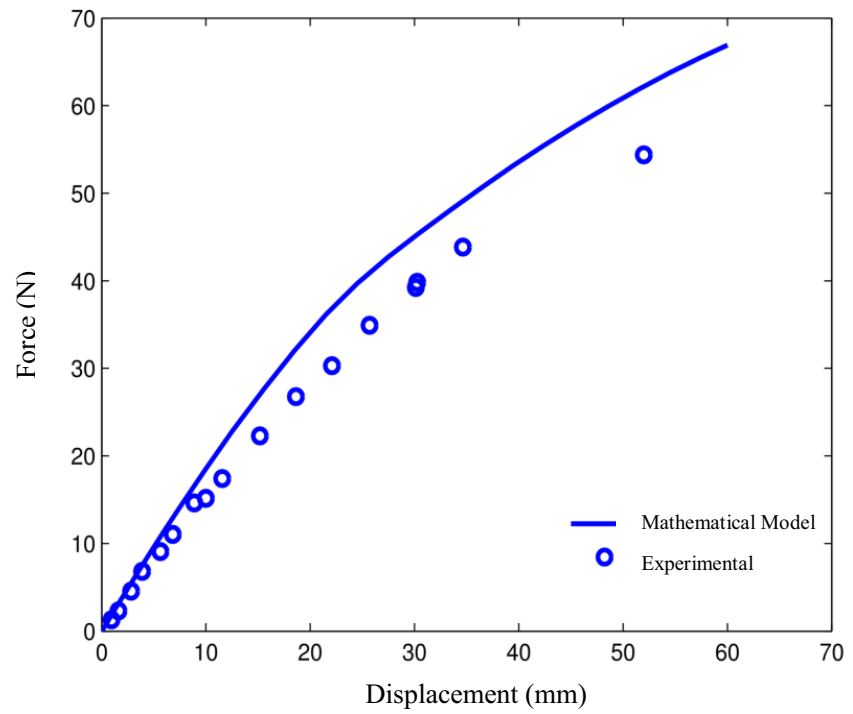

Figure 9. Force-displacement relationship for the sample bending test. 
A good correlation between simulation and experimental tests can be seen on figure 9. Motorization tests have also been run thanks to the mockup measurement setup. The motorization torque value during the deployment phase has been compared to a numerical simulation results. The model used for coiling/uncoiling phase is an analytical model that has been developed by THALES ALENIA SPACE and CNRS these last years [1]. This beam model with a flexible cross section is able to simulate the highly nonlinear and dynamic behavior of tape-springs. In this case, this fast and accurate modeling strategy is more suitable than the classical finite element shell models.
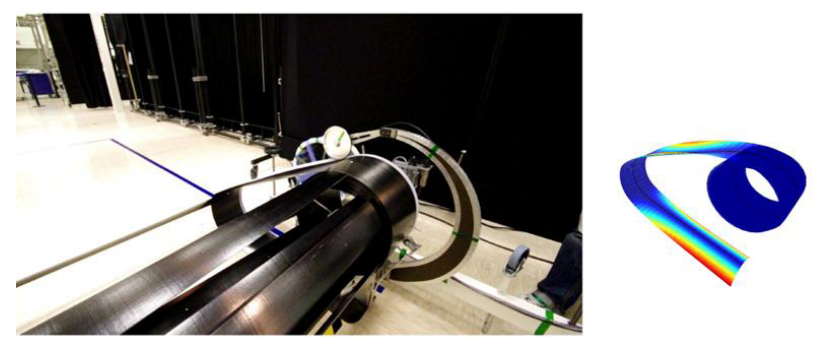

Figure 10. Compact configuration
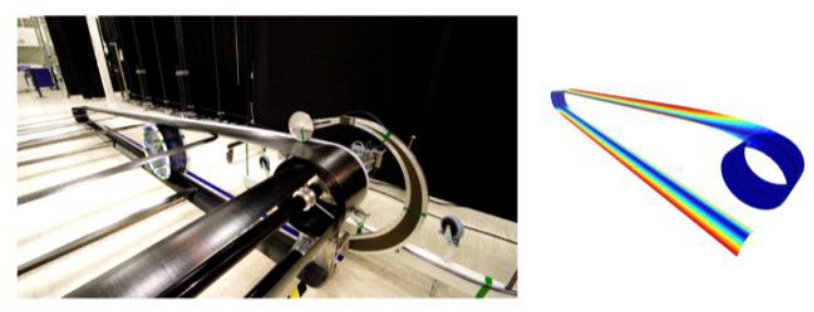

Figure 11. Deployed configuration.

Figures 10 and 11 illustrate two different steps of the deployment simulation performed with the THALES ALENIA SPACE analytical model. The computed motorization torque is compared to the experimental values. Figure 12 shows that the model is able to predict the tape-spring motorization torque with an excellent accuracy.

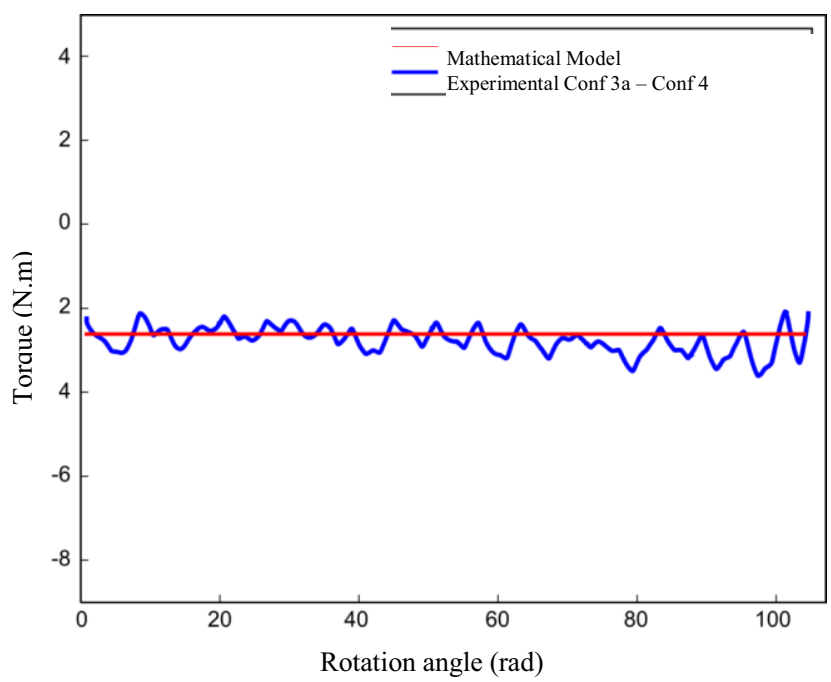

Figure 12. Torque vs. rotation relationship during deployment phase.

In addition to stiffness specifications, the tape-springs thermoelastic behavior is a crucial point in the flexible solar array design. Solar Array are long structures submitted to high thermal variation typically from $200^{\circ} \mathrm{C}$ to $+100^{\circ} \mathrm{C}$. Stability of structure is requested for sun pointing but also in order not to disturb satellite AOCS.

\subsection{Thermoelastic and other considerations}

Classic thin composite shells are usually submitted to twisting phenomena when temperature varies ; coiling is then impossible. Figure 13 shows an example of a carbon tape-spring made of a usual anti-symmetric layup. A new lay-up design has been modelled and patented by THALES ALENIA SPACE in order to solve this critical issue. Figure 14 shows the evolution of the layup design, from a highly twisted tape-spring to a very stable one.

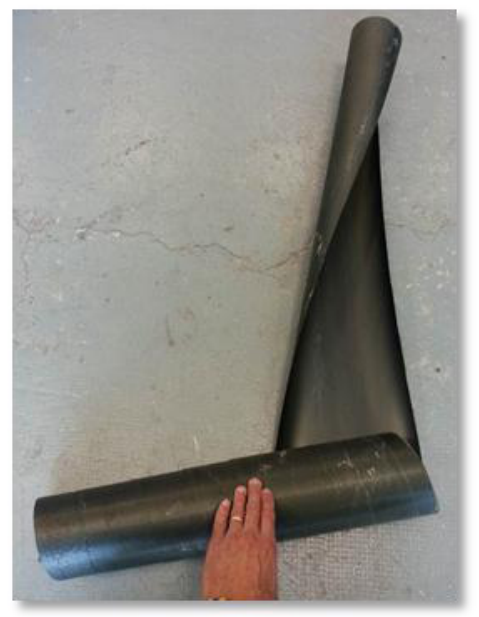

Figure 13. Twisting after thermal excursion. 

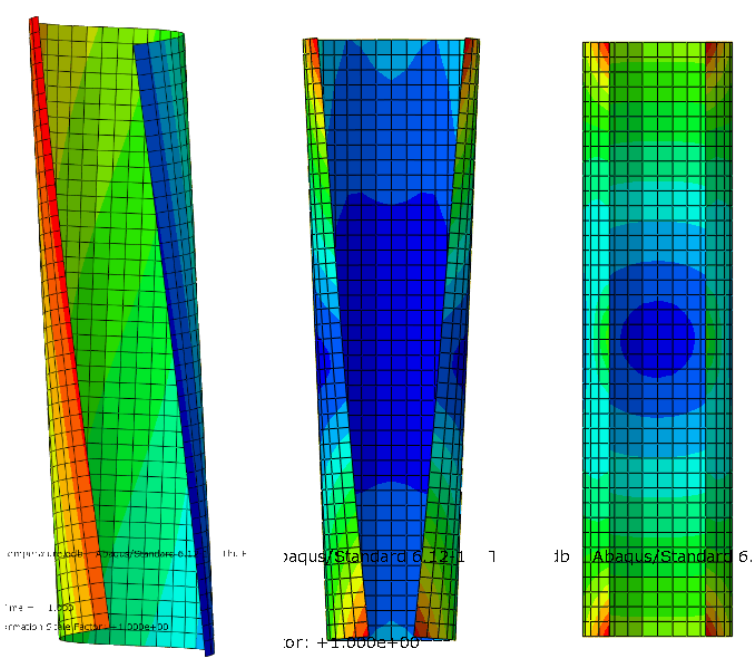

Figure 14. Simulations of 3 different layup designs in order to get rid of the twisting phenomena under $150^{\circ} \mathrm{C}$ temperature variation.

\subsection{Comparison with another concept}

The THALES ALENIA SPACE "bent into 2" tapesprings concept gives the flexible solar array structure a similar stiffness to the usual rigid panels, which is crucial for satellite attitude control. Also this solution brings a symmetrical strength to the wing, easier to manage than straight solution having a buckling limitation on one direction.

One can consider another solution using straight tapesprings. In this concept the flexible blanket is deployed from a canister located at the extremity of the solar array. So the tape-spring mass is divided by approximately 2, whereas a heavy mass is deployed. Modal analysis have been performed for comparison purpose (Table 2).

\begin{tabular}{|c|c|c|}
\hline & $\begin{array}{l}\text { Estimated mass } \\
\text { per wing }\end{array}$ & $\begin{array}{l}\text { Computed } \\
\text { frequency of } \\
1^{\text {st }} \text { mode }\end{array}$ \\
\hline $\begin{array}{l}\text { THALES } \\
\text { ALENIA } \\
\text { SPACE } \\
\text { concept }\end{array}$ & $\begin{array}{c}\text { Blanket : } 74 \mathrm{~kg} \\
\text { Tape-springs : } 29 \mathrm{~kg} \\
\text { Total : } 103 \mathrm{~kg}\end{array}$ & $0.1 \mathrm{~Hz}$ \\
\hline $\begin{array}{l}\text { Straight } \\
\text { concept }\end{array}$ & $\begin{array}{c}\text { Blanket : } 70 \mathrm{~kg} \\
\text { Tape-springs }: 12 \mathrm{~kg} \\
\text { Canister : } 5 \mathrm{~kg} \\
\text { Total }: 87 \mathrm{~kg}\end{array}$ & $0.019 \mathrm{~Hz}$ \\
\hline
\end{tabular}

Table 2. Frequencies comparison for both concepts. Considered electrical power $23.6 \mathrm{~kW}$ with 2 wings
Those simulations show that the straight concept, despite its $20 \%$ lower mass, has a 5 times lower frequency.

The additional tape-springs mass (THALES ALENIA SPACE concept) increases considerably the global stiffness as the two extremities are attached to a rigid part linked to the satellite frame, contrary to the straight concept that has a free extremity and a distant mass.

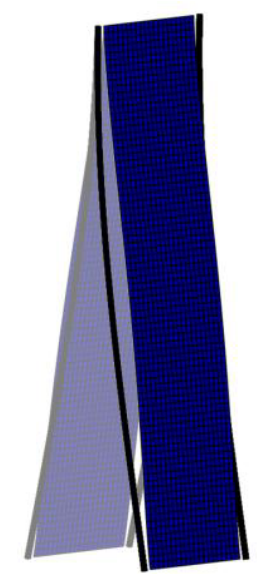

Figure 15. Modal analysis of a straight tape-spring solar array concept.

\subsection{Development conclusions}

The developments performed today for flexible mechanical architecture have been initiated with university labs (several thesis about the mechanical behaviour of tape-springs have been performed) and has been carried out with several contracts with agencies.

The development has bought and consolidated several advantages of the THALES ALENIA SPACE solution at different levels:

a/ Mechanical Architecture:

- Great and symmetrical stiffness and strength confirmed

- $\quad$ No deported mass at wing tip

- Thermo-elastic stability (no bending effect out of plane)

- One fixed point to avoid rotary electrical connection of network

- Stability versus buckling

- Bi-stable design to get an automatic stowage of TS

- New Solar Array possibility of wing rewinding / unwinding during flight

b/ Mathematical modelling:

- Non-linear FEM are now correlated with test on tape springs authorizing 
mathematical early optimization of the structure

- Bi-stable composite sizing capability demonstrated

c/ Manufacturability of long tape springs:

- Manufacturing processes:

○ Thin ply Molding

- CFRP Pull-Press Technology Successful for full scale models

d/ Mechanical architecture mock-up:

- Deployment feasibility under $1 \mathrm{~g}$ demonstrated in horizontal direction

- Functional behaviour of Tape Spring characterization

- $\quad$ Rolling capability (bi-stable)

- Synchronization of deployment

- $\quad$ Raising of interface to PVA blanket needs (lateral struts)

\section{THALES ALENIA SPACE FORECAST ON FLEXIBLE SOLAR ARRAY MARKET}

The Flexible solar array is expected to bring at the same time the following key advantages with regard to rigid array:

- Enhanced capability of power supply for equivalent mass and stowage volume, up to 50 $\mathrm{kW}$ on classical GEO platform.

- Mass reduction of about 35\% for the same power supply and network cell thickness

- Stowed bulk reduction for the same power supply.

- Recurring cost reduction about 20\% compared to classical rigid architecture thanks to simplified mechanical architecture and AIT.

- Stowage in orbit capability

Therefore, the flexible solar arrays will have interest for numerous markets including:

- GEO Telecom application having rising power demand with limited bulk under fairing, strong mass constraint and still requesting better competitiveness.

- Constellations Applications are good candidates for flexible array use while this solution is a great competitiveness lever in addition of any parallel development for network and cells cost saving. Also the stowed volume reduction can be a great advantage to increase the amount of satellites in a coupled launch.

- Missions with small satellite and high power request where the flexible compact design is a major advantage or a mandatory performance like for Space Tug mission.
- Specific missions requesting in orbit stowage: The flexible array can authorize rewinding / unwinding, for example to allow temporary high orbital loads (carrier, desorbitation, landing...), to operate next to other space vehicles (desorbiter, supply modules...) or to cross Van Allen belt.

For GEO Market the trend identified by THALES ALENIA SPACE is a progressive introduction of the flexible arrays from 2018 2020 till 2025, first for for high power payloads and later with a progressive dissemination to lower powerfull missions. The maturation of this technology will be obtained in parallel to a progressive decrease of the classic rigid architecture.

For some specific scientific missions, THALES ALENIA SPACE already identified that the feasibility of such missions relies on the use of flexible solar array due to the high power request with very limited stowage volume and mass budget.

The trend toward flexible array seems also to be confirmed by THALES ALENIA SPACE suppliers and competitors since numerous flexible array solutions are currently being developed and qualified by competitors.

\section{SUMMARY}

The work performed by THALES ALENIA SPACE with CNES support has raised the flexible architecture maturity level and demonstrated the feasibility of the patented concept with its main advantage being the simplicity of the mechanism and structure.

Also the parallel work on theoretical approach for large nonlinear structure finite element modeling and resolution combined with experimental activities has clearly demonstrated the capability of prediction by mathematical models and will authorize faster development and design performance adaptation of the tape springs.

The manufacturing of the tape spring with the requested composite layout has been demonstrated on mock-up with full scale model and so with manufacturing processes directly reusable for future flight models. This activity has then matured the manufacturing process of this "unusual" long composite structure of up to $44 \mathrm{~m}$. In addition, this manufacturing process is not limited by the length of the tape spring. The suppliers partnership has been fruitful and should naturally lead to next qualification models manufacturing.

The next step for the development of flexible solar array will consist in developping the interface of the electrical blanket with the structure and in maturing the PVA 
blanket. This will lead to the manufacturing of a first EQM combining the mechanical architecture with the electrical network and afterwards the start of environmental testing.

\section{ACKNOWLEDGMENT}

The work reported here was possible due to CNES support and ESA for support of Tape Spring technologies.

\section{REFERENCES}

Useful references to past works concerning tape spring and flexible solar array architecture are in the following list.

1. A Rod Model With Flexible Thin-Walled Cross Sections. Application To The Folding Of Tape Springs. F. Guinot, S. Bourgeois, B. Cochelin, L. Blanchard, International Journal Of Solids And Structures, Volume 49, Issue 1, January 2012, Pages 73-86.

2. Modélisation De Structures Multi-Rubans Pour Applications Spatiales. P. Marone-Hitz, B. Cochelin, S. Bourgeois, F. Guinot. Actes Du 11eme Colloque National En Calcul Des Structures, 13-17 Mai 2013, Giens. 